\title{
Prevalence of hypertension and its risk factor among cotton textile workers in low-and-middle- income countries: A systematic review protocol
}

Naureen Ali ( $\sim$ naureenalimeghani@gmail.com )

Aga Khan University Hospital

Anam Feroz

Aga Khan University Medical College Pakistan

\section{Protocol}

Keywords: Blood pressure, Hypertension, Risk-factors, Prevalence, Adult workers, Low and Middle Income Countries, Systematic Review, Cotton textile workers

Posted Date: March 30th, 2020

DOI: https://doi.org/10.21203/rs.2.24338/v2

License: (c) (1) This work is licensed under a Creative Commons Attribution 4.0 International License.

Read Full License 


\section{Abstract}

Background: Cotton workers are exposed to various hazards in the textile industry that might result in different ailments including hypertension (HTN). However, few attempts have been made to systematically review the prevalence of hypertension and its risk factor among cotton textile workers in low-and-middle-income countries (LMICs). This review aims to identify the factors and burden of hypertension; considering that modifiable factors can be prevented in this high risk population.

Methods: We will carry out the systematic literature search on the major electronic databases including PubMed, CINAHL Plus, Science Direct, and Cochrane between January 2000 and December 2019, to identify the prevalence and incidence along with risk factors of hypertension in adults' cotton textile workers in LMIC. Two researchers will independently search the databases. The search strategy will be piloted to ensure sufficient specificity and sensitivity. We will limit the search findings to human studies conducted in the adult workers.

Discussion: This review will highlight the proportion of hypertension along with its risk factor among cotton textile workers in LMICs. Given that, some of the factors can be prevented in this high-risk population, we will call on health, experts to prioritize policies and commission and conduct programs to support the improvement in their health. The findings of this review will be made publicly available and the results will be disseminated via presentations and peer-reviewed publications Conclusion: The review provides detailed information about the prevalence and risk factors of hypertension that will help to progress the health of cotton workers in LMICs.

\section{Background}

Globally, hypertension (HTN) is identified as one of the leading causes of mortality and disability (1). It has led to 7.5 million deaths and accounted for 57 million disability adjusted life years (DALYS) or 3.7\% of total DALYS(2). Hypertension is characterized as constant rise of systolic blood pressure and/or diastolic blood pressure of more than or equivalent to $140 \mathrm{mmHg}$ and/or $90 \mathrm{mmHg}$ respectively(3). Currently, around 1.13 billion individuals are suffering from hypertension globally and two-third of them resides in low- and middle-income countries (LMICs) (4) while, LMICs selection is based on World Bank's (WB) 2018 Country Classification list, having GNI per capita between $\$ 996$ and $\$ 3,895$ (5). The number of hypertensive people is projected to grow by 70 million individual from 2000 to 2025 in high income countries (HIC) while it is estimated to grow by $>500$ million in LMICs over the same period (6). A systematic review included data on 1,494,609 adults from 45 countries also showed that there is the highest burden of hypertension (32\%) in LMICs and prevalence estimates were found to be higher in elders, overweight/obese, urban settlers and having informal education (7). Moreover, worldwide high blood pressure is one of the major risk factors for cardiovascular diseases (CVD) that refers to diseases of the heart and blood vessels $(8,9)$,stroke, coronary artery disease and peripheral vascular disease (9). The burden of CVD across the world is very high and in LMICs, $47 \%$ of mortality secondary to CVDs and $44 \%$ of CVDs burden are attributable to HTN/high blood pressure (BP) $(9,10)$. Generally, it is 
asymptomatic and the primary presentation can be seen with a devastating event like stroke or heart disease (11). It is estimated that $45 \%$ of deaths with heart disease, and $51 \%$ of deaths with stroke are related to hypertension (12). This is the reason that it is referred to as the "silent killer" (11).

Worldwide, the textile industry has more than 60 million employees(13) who are involved in the production of fibers, yarns, fabrics, clothing and textile products for domestic and decoration, along with the technical and industrial purposes (14). Moreover, the textile industry involves a cluster of related industries that utilizes a range of natural fibers (cotton, wool, silk, etc.) and/or synthetic fibers to generate fabric(15) which eventually produces varying amounts of dust (16). Workers are exposed to various hazards in textile industry that might result in different ailments $(17,18)$. Studies reveal high level of oxidative stress in cotton textile workers (19)leading to the development of essential hypertension (20, 21). A study conducted in Kannur district in India found out that the prevalence of hypertension was $22.3 \%$ among cotton textile workers which was equivalent to the prevalence of general population (22). Furthermore, increasing age, alcohol consumption, family history of hypertension, BMl $>25 \mathrm{~kg} / \mathrm{m} 2$ and high waist-hip ratio were identified as a strong factor of hypertension among cotton workers(22). Similarly, a study conducted in Dhaka, Bangladesh notified that both general and central obesity were found to be significantly associated with hypertension (23). Additionally, factors such as work-related stress, noise pollution, lack of earplug usage, tobacco smoking, and long duration of employment contributes towards the development of hypertension among the cotton textile workers. $(22,24-27)$. While, stress in job also have a negative impact on worker's cardiovascular health which in turn will affect their job performance (28). However, the association between cotton dust and increased blood pressure may not be strong, as confounding factors and bias impact could not be excluded $(18,29)$

Chronic diseases make workers less productive, more prone to injury that leads to significant suffering and, add huge financial and service challenges on health care systems $(23,30-32)$. Furthermore, it is witnessed that collective monetary losses related with the hypertension, \& diabetes mellitus (DM), in low and middle-income countries are estimated to be over \$7 trillion during the years 2011-2025 that move millions of individuals below the poverty line (33). Hypertension accounts for the global burden of cardiovascular disease which evidently have huge impact on individuals, organizations and country in terms of economy (11). Therefore, early detection of hypertension by identifying its risk factors is essential among high risk population particularly in LMIC. Therefore, this systematic review aims to highlight potential risk of hypertension among cotton textile workers. Additionally, the review will also notify the magnitude of hypertension in this occupational group.

\section{Methods}

The protocol for the systematic review is registered in the International Prospective Register for Systematic Reviews (PROSPERO) [167175]. The protocol has been designed and reported based on the guidelines Preferred Reporting Items for Systematic Reviews and Meta-analyses Protocols (PRISMA-P) checklist (34). (Figure. 1). 


\section{Exclusion and inclusion criteria:}

All observational studies (cross-sectional, case-control or follow-up studies) published between 1 January, 2000 to 31 December, 2019 which reported a prevalence or incidence along with risk factors of hypertension will be included as the numbers of individual affected by hypertension is expected to increase in all areas of the world from 2000 to 2025 (35). Moreover, the recent data also suggests that prevalence of HTN has also risen in LMICs in the previous two decades (36). All adults cotton textile workers ( $\geq 18$ years) in LMICs will be included. Original articles, conference proceedings or abstracts reporting the outcome of interest will also eligible for inclusion. Articles will be excluded if the adult workers are from other than cotton textile industry. Non-English articles will not be included as the authors are not proficient in other languages. Moreover, commentaries, editorials, symposium proceedings, and systematic reviews will also be excluded.

The inclusion and exclusion criterion is shown in Table 1.

\section{Information sources and search strategy}

We will carry out the systematic literature search on the major electronic databases including PubMed, CINAHL Plus, Science Direct, and Cochrane because they are usually considered as good databases for systematic reviews. Furthermore, gray literature (non-published, non-reviewed papers internal, or online repositories) will also be searched. In addition, the bibliography of the included records will be assessed to identify relevant studies. Besides, cross-referencing of identified systematic review will also be performed to include pertinent studies. Two researchers will independently search the data bases (NA, $\mathrm{AF})$.

The search term will be group into following categories of interest: population (cotton textile, workers, factory workers, and cotton workers), exposure (risk-factors, factors, predictors, prevalence, prevalence and factors) outcome (hypertension, blood pressure, systolic blood pressure, diastolic blood pressure, hypertension, high blood pressure and HTN), and settings (LMICs). Additionally, indexed keywords in the Medical Subject Headings (MeSH) will be used in order to ensure uniform search terms. The search strategy will be piloted to ensure sufficient specificity and sensitivity. The preliminary search strategy is illustrated in Table 2. We will limit the search findings to human studies conducted in the adult cotton workers.

\section{Study selection}

Citation management system (Endnote software) will be used to manage the search results from the different databases(37). Firstly, the titles will be screened based on eligibility criteria using Endnote software. Secondly, the abstract will be screened within the short-listed studies guided by the inclusion and exclusion criteria. Lastly, the full text of potentially analyzed studies will be retrieved. For the reliability of selected studies among the two reviewers, a pre-defined screening tool will be prepared and pilot testing will be done as per the inclusion criteria. Two reviewers (NA \& AF) will describe outcome 
measures subsequently after reviewing the studies to confirm the relevance of the included articles. All studies will be given as a unique study ID to identify the data for this review. Each reviewer will give strong justification for excluding studies. Any disagreements between the two reviewers will be resolved through discussion or in consultation with a third reviewer (SF). We will contact the primary author of the study through email in case of any incomplete or missing information. The Preferred Reporting Items for Systematic Reviews and Meta-Analysis (PRISMA) flow diagram will be used to report the study selection process as given in figure 1 .

\section{Data collection process}

Data will be extracted onto a customized sheet in Excel that will be pilot tested prior to initiating the data extraction process. This sheet will be completed by two independent reviewers (NA, AF) for the eligible studies. Data extraction tables filled by two reviewers will be compared to confirm that all main findings are included. During the data extraction process a third assessor (SF) will be involved if any discordant data is witnessed. The primary data extraction table is shown in Table 3. Besides, existing studies on this research domain have been revised to assess items in the extraction form. The form included the primary author, year of publication, study setting, country of study, objective, study design, study population, male proportion, average age, BP measurement method, BP measurement apparatus, prevalence of hypertension, average BP risk-factors of hypertension co-morbidities, study limitations, included/excluded, and reason for exclusion, quality appraisal of included studies and reviewer name,

\section{Evaluation of study quality}

The quality of the included studies will be evaluated by standardized quality assessment tool which will be conducted by two authors (NA, AF). Mixed Methods Appraisal Tool (MMAT) tool will be used to evaluate the methodological quality of all non-randomized studies(38). This tool is used to assess several aspects like selection of study participant, study tool, exposure period, missing data, measurement in outcomes, and selection of the reported result. Two reviewer (NA, AF) will rate each study as critical, serious, moderate, or low risk of bias via judgment of the gathered information. If there is limited information then the risk of bias will be categorized as "no information" or the reviewer will contact corresponding study authors for complete information.

\section{Synthesis of included studies}

Firstly, we will note down the main characteristics of studies that includes study authors, publication year, study aim, study methods, sampling strategy, characteristics of study participants and study outcomes. Both reviewers (NA, AF) will read each included study several times to extract data. We will present dichotomous outcomes as relative risks, odds ratio and prevalence ratios and continuous outcomes as mean differences (MD) with SD. We will use the standardized mean difference if the continuous outcomes have been reported in diverse ways across studies. The reviewers will report the prevalence of blood pressure across different studies along with variation in the distribution of risk factors for hypertension. We will conduct a meta-analysis if the included studies are sufficiently homogenous. 
Random or Fixed effect will be yield on the insights to the data that is about the nature of the variation of included studies to account for the heterogeneity. We will also conduct a sub-group analysis under different categories including age, gender, years of service, and textile department. If the characteristics of included studies are excessively heterogeneous, we will not pool results, but we will present a narrative synthesis of the results.

\section{Discussion}

This review will highlight the proportion of hypertension along with its risk factor among cotton textile workers in LMICs. Given that, some of the modifiable factors may be prevented in this high risk population, we will call on health experts including policy makers, stake holders, cardiovascular epidemiologist and occupational health and safety specialists to prioritize policies and commission and conduct screening and awareness programs to improve worker's health. Besides, this review will highlight an urgent need for further research on hypertension in cotton textile workers that fill in some of the data gaps such as the trends and determinants of hypertension. The review findings will be made publicly available. The results of the review will be disseminated through peer-reviewed publications and presenting at professional conferences either in the form of oral or poster presentations.

\section{Abbreviations}

HTN: Hypertension; DALYS: disability adjusted life years; CVD: cardiovascular disease; LMICs: LowerMiddle-Income Countries; DM: Diabetes Mellitus; PRISMA: Preferred Reporting Items for Systematic Reviews and Meta-analyses

\section{Declarations}

Ethics approval and consent to participate

Not applicable

Consent for publication

Not applicable

Availability of data and materials

Not applicable

Competing interests

The authors declare that they have no competing interests.

\section{Funding}


Not applicable

\section{Authors' contributions}

NA has conceived and designed the study. NA has drafted the manuscript and is the guarantor of the systematic review. AF \& NA has developed the search strategy and methods of the systematic review. AF \& NA has extensively review the manuscript and incorporated intellectual inputs. All authors have read, and approved the final version of the manuscript.

\section{Acknowledgements}

The authors would like to thanks Ms. Salima Farooq, Senior Instructor, School of Nursing and Midwifery Department, The Aga Khan University, Pakistan, for providing supervision as a third reviewer in case of any disagreement between two reviewers.

\section{References}

1. Forouzanfar MH, Liu P, Roth GA, Ng M, Biryukov S, Marczak L, et al. Global burden of hypertension and systolic blood pressure of at least 110 to 115 mm Hg, 1990-2015. Jama. 2017;317(2):165-82.

2. World Health Organization. Global Health Observatory (GHO) data. Raised blood pressure, Situation and trends. https://www.who.int/gho/ncd/risk_factors/blood_pressure_prevalence_text/en/.

3. Chobanian AV, Bakris GL, Black HR, Cushman WC, Green LA, Izzo Jr JL, et al. The seventh report of the joint national committee on prevention, detection, evaluation, and treatment of high blood pressure: the JNC 7 report. Jama. 2003;289(19):2560-71.

4. World Health Organization (WHO, 2019). Hypertension; Key-facts. https://www.who.int/newsroom/fact-sheets/detail/hypertension.

5. Bank W. World Bank Country and Lending Groups. LOWER-MIDDLE-INCOME ECONOMIES $(\$ 1,006$ TO $\$ 3,955) 2018$.

6. Perkovic V, Huxley R, Wu Y, Prabhakaran D, MacMahon S. The burden of blood pressure-related disease: a neglected priority for global health. Hypertension. 2007;50(6):991-7.

7. Sarki AM, Nduka CU, Stranges S, Kandala N-B, Uthman OA. Prevalence of hypertension in low-and middle-income countries: a systematic review and meta-analysis. Medicine. 2015;94(50).

8. Chiolero PBA. Prevalence and control of hypertension. THE LANCET. 2018; 392(10155):1305-6.

9. Roth GA, Johnson C, Abajobir A, Abd-Allah F, Abera SF, Abyu G, et al. Global, regional, and national burden of cardiovascular diseases for 10 causes, 1990 to 2015. Journal of the American College of Cardiology. 2017;70(1):1-25.

10. Horsa BA, Tadesse Y, Engidawork E. Assessment of hypertension control and factors associated with the control among hypertensive patients attending at Zewditu Memorial Hospital: a cross sectional study. BMC research notes. 2019;12(1):152. 
11. Ofori SN, Obosi J. Prevalence of hypertension among office workers in a multi-national company in the Niger-Delta with the 2017 American College of Cardiology/American Heart Association Blood Pressure Guidelines. Preventive medicine reports. 2019;15:100899.

12. World Health Organization. A global brief on hypertension. WHO/DCO/ WHD/2013.2. Geneva: WHO 2013. Available from http://www.who.int/cardiovascular_diseases/publications/global_brief_hypertension/en/.

13. Forstater M, Implications of the global financial and economic crisis on the textile and clothing sector. International Labour Organization. International Labour Office, Geneva, 2009.

14. Bullón J, González Arrieta A, Hernández Encinas A, Queiruga Dios A. Manufacturing processes in the textile industry. Expert Systems for fabrics production. 2017.

15. Moses JJ, Ammayappan L. Growth of textile industry and their issues on environment with reference to wool industry. Asian Dyer. 2006;3:61-7.

16. Nafees AA, Fatmi Z, Kadir MM, Sathiakumar N. Pattern and predictors for respiratory illnesses and symptoms and lung function among textile workers in Karachi, Pakistan. Occup Environ Med. 2013;70(2):99-107.

17. Ali NA, Nafees AA, Fatmi Z, Azam SI. Dose-response of Cotton Dust Exposure with Lung Function among Textile Workers: MultiTex Study in Karachi, Pakistan. The international journal of occupational and environmental medicine. 2018;9(3):120.

18. ZIA S, JAVEED S, JAN F. Pathophysiological Effects of Cotton Dust Pollution on Blood Pressure in Textile Workers. Cell.300:6617901.

19. Suryakar A, Katkam R, Dhadke V, Bhogafe R. A study of oxidative stress in cotton industry workers from Solapur city. Biomedical Research. 2010;21(3):260-4.

20. Rodrigo R, Prat H, Passalacqua W, Araya J, Guichard C, Bächler JP. Relationship between oxidative stress and essential hypertension. Hypertension Research. 2007;30(12):1159.

21. Briones AM, Touyz RM. Oxidative stress and hypertension: current concepts. Current hypertension reports. 2010;12(2):135-42.

22. Ismail IM, Binub K. Prevalence of hypertension and its associated factors among cotton textile workers of Kannur, Kerala. Menoufia Medical Journal. 2016;29(4):991.

23. Bhowmik B, Afsana F, Ahmed T, Akhter S, Choudhury HA, Rahman A, et al. Obesity and associated type 2 diabetes and hypertension in factory workers of Bangladesh. BMC research notes. 2015;8(1):460.

24. Rizi HAY, Dehghan H. Effects of occupational noise exposure on changes in blood pressure of workers. ARYA Atherosclerosis. 2013:183-6.

25. Starzyński Z, Wilczyńska U, Kubasiewicz M, Szymczak W. Incidence of arterial hypertension in the population of workers in the textile industry in Lódź. Medycyna pracy. 1985;36(2):131-8.

26. Tiwai R, Pathak M, Zodpey S, Babar V. Hypertension among cotton textile workers. Indian journal of public health. 2003;47(1):34-6. 
27. Sumardiyono S, Hartono H, Probandari A, Setyono P. The Association between Risk Factors and Blood Pressure in the Textile Industry Workers. Global Medical \& Health Communication. 2017;5(3):228-35.

28. Kitronza PL, Mairiaux P. Occupational stress among textile workers in the Democratic Republic of Congo. Tropical medicine and health. 2015.

29. Koskela R, Klockars M, Järvinen E. Mortality and disability among cotton mill workers. Occupational and Environmental Medicine. 1990;47(6):384-91.

30. Luckhaupt SE, Cohen MA, Li J, Calvert GM. Prevalence of obesity among US workers and associations with occupational factors. American journal of preventive medicine. 2014;46(3):237-48.

31. Safety A, Council C. Overweight and Obesity: Implications for Workplace Health and Safety and Workers' Compensation: Australian Safety and Compensation Council; 2008.

32. Di Lorenzo L, De Pergola G, Zocchetti C, L'Abbate N, Basso A, Pannacciulli N, et al. Effect of shift work on body mass index: results of a study performed in 319 glucose-tolerant men working in a Southern Italian industry. International journal of obesity. 2003;27(11):1353.

33. Bloom DE, Chisholm D, Jané-Llopis E, Prettner K, Stein A, Feigl A. From burden to" best buys": reducing the economic impact of non-communicable disease in low-and middle-income countries. Program on the Global Demography of Aging, 2011.

34. Moher D, Shamseer L, Clarke M, Ghersi D, Liberati A, Petticrew M, et al. Preferred reporting items for systematic review and meta-analysis protocols (PRISMA-P) 2015 statement. Systematic reviews. 2015;4(1):1.

35. Kearney PM, Whelton M, Reynolds K, Muntner P, Whelton PK, He J. Global burden of hypertension: analysis of worldwide data. The lancet. 2005;365(9455):217-23.

36. Ibrahim MM, Damasceno A. Hypertension in developing countries. The Lancet. 2012;380(9841):6119.

37. Xiehang CDL. Evaluation and prospect of reference management software--a case study of EndNote and NoteExpress. New Technology of Library and Information Service. 2009:Z1.

38. Sterne JA, Hernán MA, Reeves BC, Savović J, Berkman ND, Viswanathan M, et al. ROBINS-I: a tool for assessing risk of bias in non-randomised studies of interventions. bmj. 2016;355:i4919.

\section{Tables}

Table 1 Eligibility criteria 


\begin{tabular}{|c|c|c|}
\hline ibute & Inclusion Criteria & Exclusion Criteria \\
\hline dlation & $\begin{array}{l}\text { Studies involving adult } \\
\text { cotton textile workers of } \\
\text { both genders }\end{array}$ & $\begin{array}{l}\text { Studies involving target groups of adult } \\
\text { workers working in another factory mill (oil } \\
\text { mill, steel mill and coal mill) }\end{array}$ \\
\hline ies & $\begin{array}{l}\text { Observational studies } \\
\text { (survey, descriptive, cross- } \\
\text { sectional cohort and case } \\
\text { control study and brief } \\
\text { communication studies } \\
\text { having full-text article) }\end{array}$ & $\begin{array}{l}\text { RCT and quasi-experimental study, Qualitative } \\
\text { formative studies, systematic reviews case } \\
\text { studies, protocols, commentaries, editorials, } \\
\text { unpublished articles, symposium proceedings, } \\
\text { conference abstracts and irretrievable } \\
\text { documents }\end{array}$ \\
\hline ;ome & $\begin{array}{l}\text { Studies demonstrating } \\
\text { outcomes related to } \\
\text { prevalence, incidence along } \\
\text { with risk factor of } \\
\text { hypertension }\end{array}$ & $\begin{array}{l}\text { Studies demonstrating outcomes in workers } \\
\text { having different comorbidity }\end{array}$ \\
\hline ing & Studies conducted in LMICs & Studies conducted elsewhere \\
\hline yuage & $\begin{array}{l}\text { Studies available in the } \\
\text { English Language }\end{array}$ & Studies in other languages \\
\hline $\mathrm{od}$ & $\begin{array}{l}\text { Studies published between } \\
\text { the period of } 1 \text { January, } \\
2000 \text { to } 31 \text { December, } 2019\end{array}$ & $\begin{array}{l}\text { Studies published out of the period of } 2000 \text { to } \\
2019\end{array}$ \\
\hline Jurces & $\begin{array}{l}\text { Systematic literature search } \\
\text { on the major electronic } \\
\text { databases including } \\
\text { PubMed, CINAHL Plus, } \\
\text { Science Direct, and } \\
\text { Cochrane }\end{array}$ & $\begin{array}{l}\text { Systematic literature search other than these } \\
\text { electronic databases including PubMed, } \\
\text { CINAHL Plus, Science Direct, and Cochrane }\end{array}$ \\
\hline
\end{tabular}


Table 2: Search strategy

\begin{tabular}{|l|l|}
\hline Population & $\begin{array}{l}\text { ('textile* [Mesh] OR 'workers*' OR 'factory worker*' OR 'mill worker'* OR } \\
\text { 'male worker*'OR ' cotton worker*' [Mesh]) AND }\end{array}$ \\
\hline Exposure & $\begin{array}{l}\text { ('Risk-factors' OR 'factors' OR 'predictors' OR 'prevalence' OR 'incidence' } \\
\text { 'risks', 'prevalence and factors') AND }\end{array}$ \\
\hline Outcome & $\begin{array}{l}\text { Outcome ( 'hypertension' OR 'blood pressure' OR 'systolic blood pressure' } \\
\text { OR 'diastolic blood pressure' OR hypertension* OR high blood pressure OR } \\
\text { HTN) AND }\end{array}$ \\
\hline Setting & Studies conducted in LMIC \\
\hline Filters & Publication date from 1 January, 2000 to 31 December, 2019; Humans \\
\hline
\end{tabular}

Table 3 Data Extraction Table 


\begin{tabular}{l|l|l|l|l|l|l|l|l|}
\hline haracteristics & $\begin{array}{l}\text { Study } \\
\mathbf{2}\end{array}$ & $\begin{array}{l}\text { Study } \\
\mathbf{2}\end{array}$ & $\begin{array}{l}\text { Study } \\
\mathbf{3}\end{array}$ & $\begin{array}{l}\text { Study } \\
\mathbf{4}\end{array}$ & $\begin{array}{l}\text { Study } \\
\mathbf{5}\end{array}$ & $\begin{array}{l}\text { Study } \\
\mathbf{6}\end{array}$ & $\begin{array}{l}\text { Study } \\
\mathbf{7}\end{array}$ & $\begin{array}{l}\text { Study } \\
\mathbf{8}\end{array}$ \\
\hline tudy Author \& & & & & & & & & \\
\hline ear & & & & & & & & \\
\hline etting \& Country & & & & & & & & \\
\hline tudy Aim & & & & & & & & \\
\hline tudy Design Population & & & & & & & & \\
\hline Iale proportion & & & & & & & & \\
\hline verage age & & & & & & & & \\
\hline verage BP & & & & & & & & \\
\hline p Measurement & & & & & & & & \\
lethods & & & & & & & & \\
\hline p Measurement \\
pparatus
\end{tabular}

Figures 
Studies identified through database

searching

$(n=)$

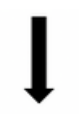

Studies included by screening relevant titles after de-duplication

$$
(n=)
$$
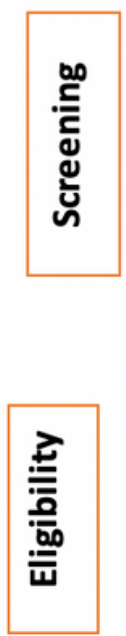

Studies included by screening abstract $(n=)$

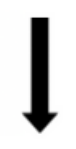

Studies reviewed for relevant full-text papers $(n=)$

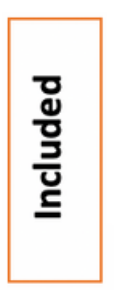
Studies identified from crossreferencing

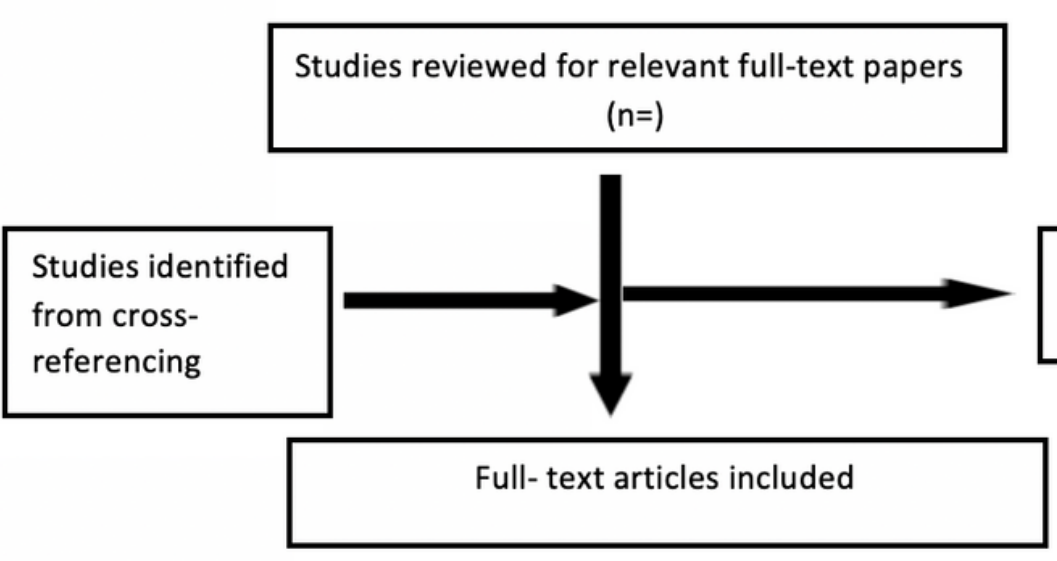

Duplication excluded

$$
(n=)
$$

Titles excluded for not meeting the eligibility criteria

$(n=)$

Abstracts excluded for not meeting the eligibility criteria

$(n=)$

Abstracts unavailable

$(n=)$
Full text excluded for not meeting the eligibility criteria $(n=)$

Figure 1

PRISMA Flow Diagram for Database Search of Studies 